\title{
EFFECT OF INSTRUCTIONAL PROGRAM ON KNOWLEDGE REGARDING VULVOVAGINAL CANDIDIASIS AMONG FEMALE UNIVERSITY STUDENTS
}

\author{
Amel Dawod Kamel Goudia ${ }^{1 *}$, Abeer Saad Eswi ${ }^{1}$, Azza Ali Abd El Hamid ${ }^{1}$, Soumaya Mohamed \\ Hassan $^{2}$ \\ ${ }^{1}$ Maternal \& New Born Health Nursing Department Faculty of Nursing,Cairo University, Al Orman، Giza \\ Governorate, Cairo, Egypt 12613 \\ ${ }^{2}$ Obstetrics and Gynecology Faculty of Medicine Cairo University, Al Orman، Giza Governorate, Cairo, \\ Egypt 12613 \\ *Dawod_m3@yahoo.com
}

\begin{abstract}
Adolescents learn about Vulvo vaginal candidiasis (VVC) because its common clinical problem in female during this age throughout the world particularly in hot, subtropical climates. Education in health is one of the key components of primary health care and one of the most vital health care requirements for female that must be considered much more in the primary health care system, particularly maternal and child health. To assess the knowledge of female university students about (VVC) and examine the effect of instructional program on their knowledge regarding Vulvovaginal Candidiasis among female university students. A quasi-experimental design "time-series" will be utilized to achieve the aim of current study. The current study was conducted at Cairo University hostel were the female students were residing and selected from non medical faculties. A simple random sample of 100 female university students was recruited for this study. Two tools were used to collect the study data; structured interview tool, and "VVC" structured knowledge assessment

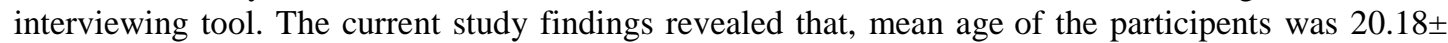
1.19 years. More than two thirds of them fell in the age range 20-24 years. Regarding menstrual characteristics among the participants, age range at menarche was 11-14 years with a mean of \pm SD was $(12.30 \pm 1.88)$ years, duration of menstruation ranged between 2-6 days with a mean of $(4.23 \pm 1.25)$. The total mean knowledge score of (VVC) was $18.87 \pm 7.83$ out of $/ 85$ in the pretest; which indicated poor knowledge level and $81.20 \pm 5.01$ in posttest after two weeks from instruction program; which indicated good knowledge level that remain good knowledge in the post test (2) with a mean of $74.35 \pm 6.68$ after eight weeks from instruction program, and $62.85 \pm 6.89$ in the post test (3) after 12 weeks from weeks from instruction program; which indicated satisfactory knowledge level with high statistical significant differences $(\mathrm{P}=0.001)$. The instructional program had positive effect on knowledge and awareness regarding (VVC) among female university students and this results hence the research hypotheses.
\end{abstract}

Keywords: instructional program, vulvovaginal candidiasis, female university students

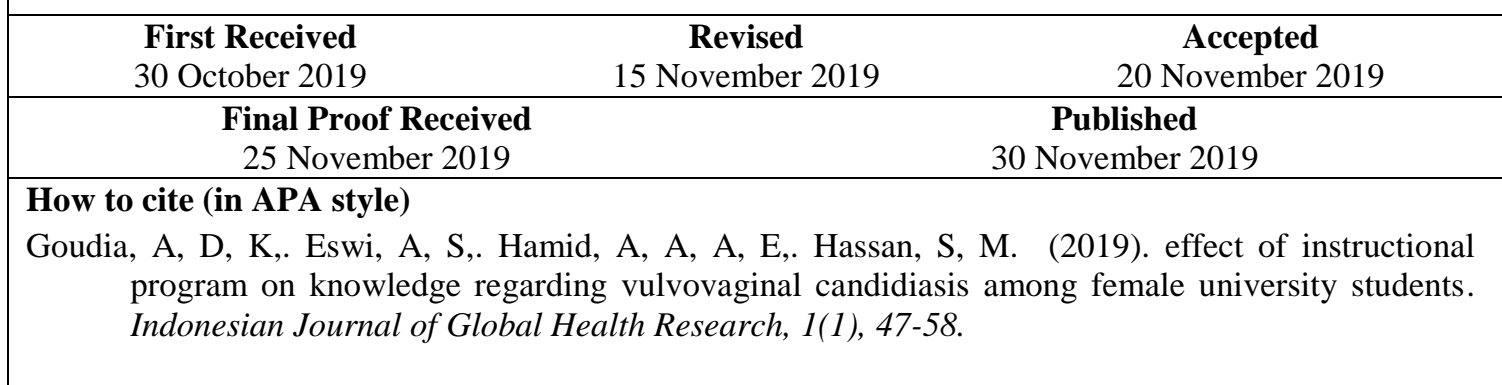

\section{INTRODUCTION}

Vulvovaginal Candidiasis is one of the most common causes of vaginal infection and, remains a significant problem among female. It is estimated that $75 \%$ of female will experience at least one episode in their lifetime, with a $50 \%$ of all female experiencing 
multiple episodes. Reproductive hormones in adolescents cause vast changes in tissues increase the susceptibility to (VVC). In recent years, it has become more common for young to consult health centers because of vulvar discomfort and abnormal vaginal discharge that probably develop a chronic pain syndrome or vulvar vestibulitis (Joes \& Rue, 2008, and Mercola, 2008).

VVC is common among girls because of lifestyle patterns such as wearing tight pants/jeans; using one napkin for a prolonged time during menstruation. Using scented sanitary, products hi-fi deodorant chemicals; using unclean mugs and buckets for perineal wash can irritate the vagina, and douching can upset the healthy balance of bacteria in the vagina. Other predisposing factors include diabetes mellitus, oral steroid use, broad-spectrum antibiotics, immunosuppressant diseases, diet especially for carbohydrates "yeast's favorite food" and foods that contain hydrogenated and partially hydrogenated oils stimulate Candida growth and caffeine as well as obesity or excessive weight, In addition, ; heat and moisture might make yeast infections more likely because yeast can thrive in this type of environment, and some women probably have a mild Candida antigen-specific immunologic deficiency. There is no direct association between yeast infection and other sexual transmitted disease $\left(\mathrm{STD}_{\mathrm{S}}\right.$. (Berek, 2007; Jinping et al, 2008 and Meena, 2011).

VVC is associated with considerable morbidity and health care cost. In Egypt, a study done by kamel, (2011), to assess common types of vaginal infections among women attending gynecology clinics at El Mainal University Hospital reported that, the prevalence of vaginal infections was $58.8 \%$. Vulvo- vaginal Candidiasis was diagnosed in $41 \%$, Bacterial Vaginosis was identified in 10.2\%, $6 \%$ had Trichomonas Vaginalis, and $1.6 \%$, had mixed infection. Knowledge of how to prevent vaginal Candidiasis could save many female from frequent office visits and uncomfortable vaginal infections and prevent complications of it. Current theories suggest certain measures that may be beneficial, such as keeping the vaginal area clean and dry and avoiding large amounts of refined carbohydrates. However, Nurses and other health care providers often offer advice to female in the form of changes in diet and personal hygiene practices in an effort to prevent VVC (Rylander, Berglund \& Krassny, 2004).

According to Rao, \& Shriyan, (2005), the study of level of knowledge and practice about genital infections among 100 females in the age group between 15-40 years are reported that more than $70 \%$ have not knowledgeable regarding infections of genital area; most $(80 \%)$ of them felt that discharge from the vagina is leaking out of bone; and $90 \%$ of them were not aware about the dietary habits that promote vaginal health. VVC complications are pelvic inflammatory diseases, infertility, pelvic abscess, temporary or absolute endometritis, menstrual disorder, urinary tract infection, ectopic pregnancy, spontaneous abortion and premature birth, and postpartum infection (Marcia, Patricia, Ball \& Bindeler, 2008 ; and Ricci, \& Kyle, 2011).

The nurse plays an important role as health educator; who has to deliver important health educational topics to the female students as diet, personal hygiene, increasing immunity, and proper way of medication use to limit recurrences of that infection and prevent subsequent complications. The nurse should perform careful assessment of common signs, symptoms of vaginal Candidiasis, and presence of risk factors such as 
improper diet, antibiotics, immunosuppressive condition, and improper personal hygiene. Health professionals caring for female patient should find out symptoms of VVC and give them knowledge to be aware in order to help them in improving their health by adopting preventive measures that help in reducing the incidence and avoiding the complications of VVC. (Gurewitsch, 2008; \& Ricci, \& Kyle, 2011, and, Kamath, etal , 2014).

The aim of the current study was to assess the knowledge of female university students about Vulvovaginal Candidiasis and examine the effect of instructional program on their knowledge regarding Vulvovaginal Candidiasis.

\section{METHOD}

The quasi-experimental design "time-series" was utilized to achieve the aim of current study. Time quasi-experimental series design. It measures the same variables at different points of time (Derue, \& Scott, 2012, and Nieswidomg, 2012). This study was conducted at Cairo University Hostel where the female students were residing. A simple random sample consisting of 100 female university students was recruited for this study according to the following inclusion criteria: student from non medical faculties; age from 18 to 24 years, single and willing to participate in the study, and not complaining from VVC. While, The exclusion criteria was: The student who had any educational program on Vaginal Candidiasis during the past six months.

Two tools were developed by researcher after extensive review of the relevant literature and utilized for data. Tool 1: Structured Interview Tool. This tool was included two parts: the first part contained questions related to personal data as; code, age, residence, level of university education, telephone number. The second part contained data related to menstrual history as; age of menarche, regularity of menses, frequency, duration, and amount of blood loss. Tool 2: Vulvovaginal Candidiasis structured knowledge assessment interviewing tool. This tool used in pretest and follow up post test. It consists of eight suction with a total score 85 included open ended questions related to anatomy of female reproductive, questions related VVC infection, questions related predisposing factors of VVC ms, questions related symptoms of VVC questions related diagnosis of VVC which, questions related treatment of VVC which, questions related complications of VVC which includes 6 items, and questions related prevention of VVC which includes 20 items.

Scoring system: for knowledge a score of (0) for no answer and incorrect answer and score (1) for correct answer with a total scores 85; a total score of seventy five percent or more $(\geq 75 \%)$ considered as good level of knowledge, and a total score of fifty to seventy four percent (50-74\%) considered as satisfactory level of the study. Female students ensured that participation in this study will be voluntary and confidentiality and anonymity of each subject was assured through coding of all data and they had the right to withdraw from the study at any time without any rationale. Consequently, written consent was obtained from them.

The current study was conducted through four phases. Interview phase: In this phase, the investigator met the female university students who met the inclusion criteria then, interviewed them individually to collect personal data, and menstrual history. 
Assessment phase: In this phase, the investigator obtained the baseline assessment data regarding the knowledge about VVC through using VVC structured knowledge assessment interviewing tool "pretest" which took about 20-25 min for each group "self administer tool". Implementation phase: Immediately after assessment phase the investigator started the first session. The recruited students were divided into five groups with average number of 20 students attending the session. The investigator conducted the program entitled of "Vulvovaginal Candidiasis and new strategies of prevention". The program contained overview about anatomy of reproductive system; characteristics of normal vaginal discharge; definition; incidence; etiology, predisposing factors; clinical manifestations; treatment; complications, and prevention of VVC. The program was conducted in three sessions per week for each group, one-day interval between each session. The investigator used power point presentation and video during explanation to grasp the student's attention. Each session consumed about 30-45 minutes. Follow up and Evaluation phase: Post-test was administered to follow up knowledge gained after two weeks from implementation of the instructional program then after eight weeks, and finally after twelve weeks. This posttest consumed about 15$20 \mathrm{~min}$ for each student. All students were permitted to ask questions for clarification of any statement that she did not understand. The investigator also recorded any complaints or needs.

\section{RESULTS}

Finding of the study revealed, the average age of the participant ranged between 18-23 years old with a mean of $20.18 \pm 1.19$ year. Approximately three quarter of the female university student fell in age class 20-24 years while; low percentage of them fell in the age class $>20$ years. Regarding to their residence, $63 \%$ of the sample were residing rural areas, while $37 \%$ of them residing in urban areas. In relation to the type of faculties included in the study, $41 \%$ from Faculty of Dar El-ulum while only, 5\% of them were from Faculty of Commerce (table, 1).

Regarding to the menstrual characteristics among the female university students age range at menarche was 11-14 years with a mean \pm SD was $(12.30 \pm 1.88)$ years. Concerning the duration of menstruation ranged between 2-6 days with a mean \pm SD was $(4.23 \pm 1.25) ; 31 \%$ of them ranged from 2 to $>4$ days, and $69 \%$ were ranged $4-6$ days (Figure, 4).Regarding to menstrual regularity, $66 \%$ of them had regular menstruation rhythm. Therefore more than two third of female university students had moderate amount of the menstruation

\section{Description of sample based on pre-test post-test Knowledge scores}

Figure (1) clarifies total and subtotal mean knowledge scores of the female university students regarding Vulvovaginal Candidiasis: shows that total knowledge was analyzed by the total of knowledge question answered correctly on Vulvovaginal Candidiasis knowledge test. The average of the total Vulvovaginal Candidiasis knowledge score of female university student was found to be $18.87 \pm 7.83$ in pretest; which indicated poor knowledge level $(22.2 \%)$ and $81.20 \pm 5.01$ in posttest after two weeks from instruction program; which indicated to an improvement in knowledge level to become good knowledge level (95\%). Moreover, mean score of knowledge after eight weeks from instruction program was 74.35 \pm 6.68 ; which indicated good knowledge level, and $62.85 \pm 6.89$ after 12 weeks from weeks from instruction program; which indicated 
satisfactory knowledge level. To analyses the difference between pre test (base line knowledge) and post test (I), /post test (2) /, and post test (3) knowledge scores, repeated measurement ANOVA were calculated and showed statistically significant difference $\mathrm{F}=1.49$, $=0.001$ regarding the knowledge level about Vulvovaginal Candidiasis on the pretest and subsequent posttest.

Table (2) distribution of the female university students regarding their level of knowledge score about Vulvovaginal Candidiasis during pretest and posttest (I): level of knowledge categories was analyzed by the total of knowledge question answered correctly on Vulvovaginal Candidiasis knowledge tool. To analyses the difference between pre test and post test (1) knowledge level scores, Ninety five percent of the studied sample had good level of knowledge about Vulvovaginal Candidiasis during the post- test after two weeks from the program. The total mean score of e knowledge were (81.20 out of 85) after two weeks of the program ; which indicated to an improvement in knowledge level to became good knowledge level as compared to $18.87 \pm 7.83$ out of 85 ; which indicated poor knowledge level before start the program (table, 12 \& figure, 6).comparison on using paired t- test revealed highly statistically significant difference in the total knowledge score level of Vulvovaginal Candidiasis on the pretest and posttest after two weeks from program $\mathrm{t}=-67.6 \quad \mathrm{P}=0.001$.This results hence the hypothesis (I) is accepted (Figure, 2).

Table (3) distribution of the female university students regarding their level of knowledge score about Vulvovaginal Candidiasis during posttest (I) and posttest (2): the total score of the knowledge were ( 81.20 out of 85 ) after two weeks of the program as compared 74.35 out of 85 after eight weeks from program which indicated good knowledge. Pair comparison using paired t- test revealed highly statistically significant difference $\mathrm{t}=8.09 \mathrm{P}=0.001$. This result hence and support the hypothesis (II) is accepted (Figure, 3).

Table (4) distribution of the female university students regarding their level of knowledge score about Vulvovaginal Candidiasis during posttest (I) and posttest (3): the total score of the knowledge were $(81.20 \pm 5.01$ out of 85$)$ after two weeks of the program as compared 62.85 out of 85 after twelve weeks from program (Figure, 4).; which indicated satisfactory knowledge level Pair comparison using paired t- test revealed highly statistically significant difference in the total knowledge score level of Vulvovaginal Candidiasis on the posttest after two weeks from program and post test after twelve weeks from the program $\mathrm{t}=22.58 \mathrm{P},=0.001$. This study results in relation to the score of the post test (1) after two weeks, and posttest (3) after twelve weeks from the program supported the hypothesis (II) through the findings of the previous results. 


\section{Table 1.}

Distribution of the female university students regarding personal data $(n=100$

\begin{tabular}{|l|c|c|}
\hline \multicolumn{1}{|c|}{ Demographic characteristics } & f & $\%$ \\
\hline Age Categories (years old): & 28 & 28 \\
$\leq 20$ & 72 & 72 \\
\hline $20-24$ & \multicolumn{2}{|c|}{$20.18 \pm 1.19$} \\
\cline { 2 - 3 } Mean \pm SD & 63 & 63 \\
\hline Residence: & 37 & 37 \\
Rural & & \\
Urban & 41 & 41 \\
\hline Faculties included: & 20 & 20 \\
\hline Faculty of Dar El-ulum & 14 & 14 \\
Faculty of Kinder garden & 12 & 12 \\
Faculty of economic \& political Science & 8 & 8 \\
Faculty of Law & 5 & 5 \\
Faculty of Archeology & \multicolumn{2}{|c|}{} \\
Faculty of Commerce & \multicolumn{2}{|c|}{} \\
\hline
\end{tabular}

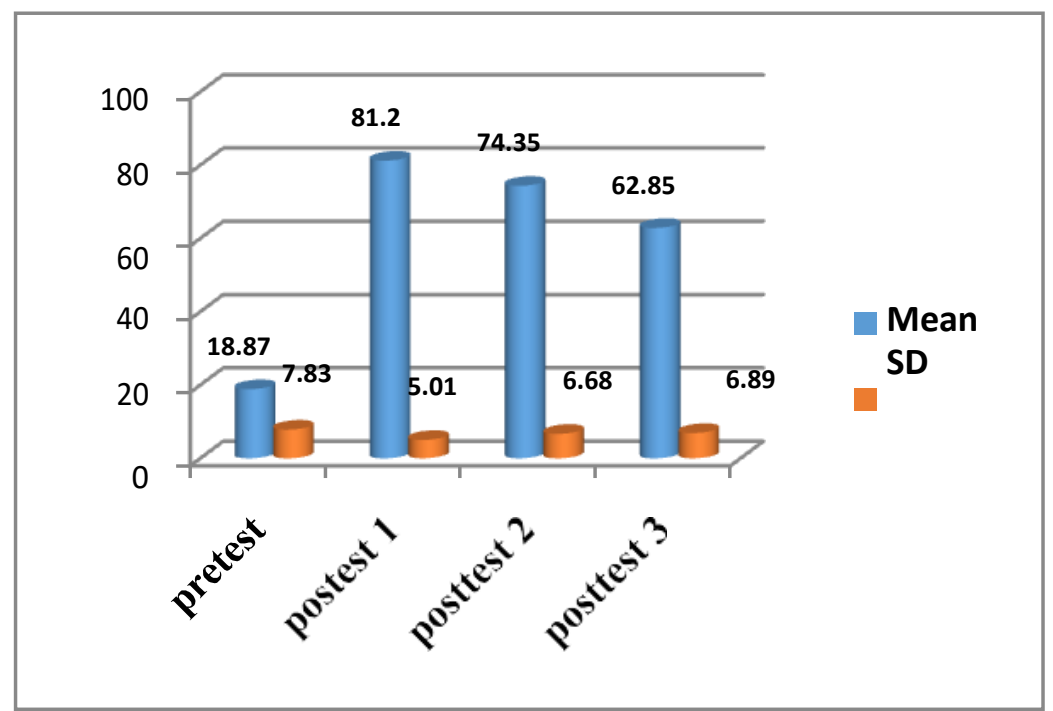

Figure 1.

Istribution of female university students regarding their knowledge of Vulvovaginal candidiasis during pre test and subsequent posttest

\section{Table 2.}

Distribution of the female university students regarding their level of knowledge score about Vulvovaginal Candidiasis during pretest and posttest $(n=100)$

\begin{tabular}{|l|l|c|}
\hline Knowledge Regarding VVC & Pre test & Post test (I) at 2 wks \\
\hline Total mean knowledge score & $\begin{array}{c}18.87 \pm 7.83 \\
\text { Poor }\end{array}$ & $81.20 \pm 5.01$ \\
& \multicolumn{2}{|r|}{$\mathrm{t}=-67.6 \mathrm{P}=0.001$} \\
\cline { 2 - 3 }
\end{tabular}




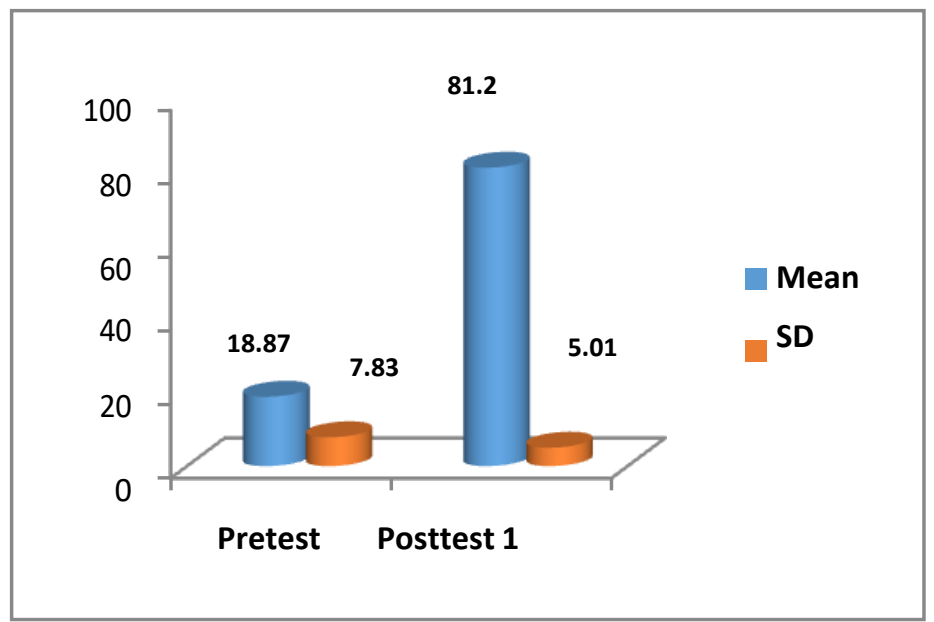

Figure 2.

Distributions of the female university students regarding their level of knowledge score about Vulvovaginal Candidiasis during pretest and posttest

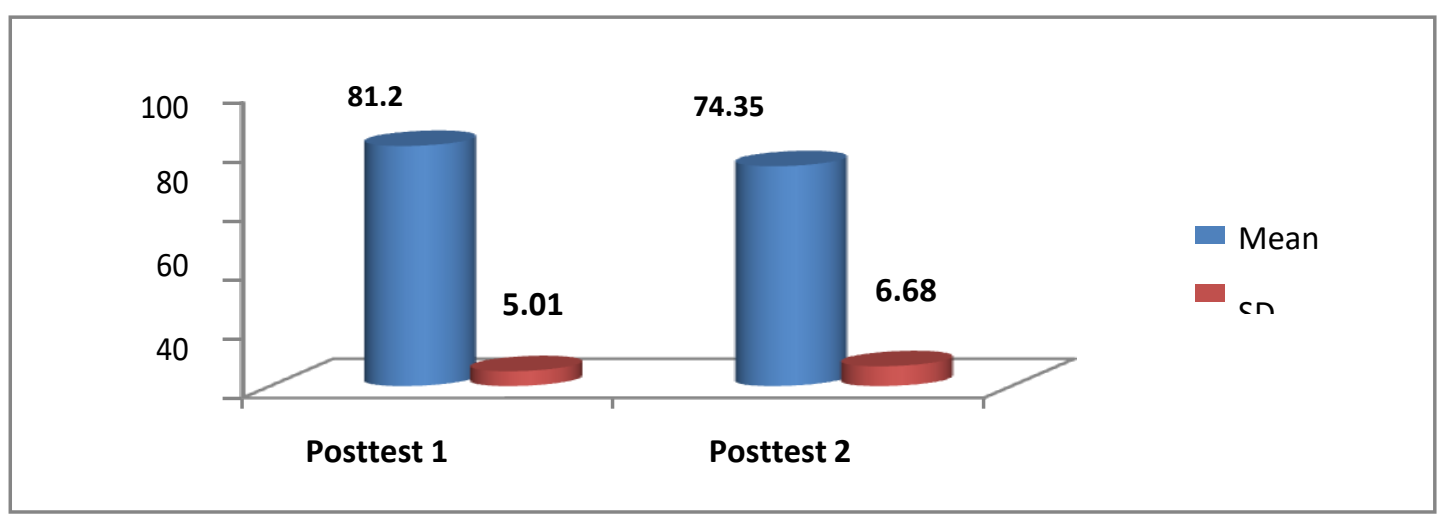

Figure 3.

Distributions of the female university students regarding their level of knowledge score about Vulvovaginal Candidiasis during posttest (1) and post test (2).

Table 3.

Distribution of female university students regarding their level of knowledge score about Vulvovaginal Candidiasis during posttest (1) and posttest (2) (n=100)

\begin{tabular}{|l|c|c|}
\hline Knowledge Regarding VVC & Posttest (1)at 2 wks & Post test (2) at 8wks \\
\hline \multirow{2}{*}{$\begin{array}{l}\text { Total mean knowledge } \\
\text { score }\end{array}$} & $81.20 \pm 5.01$ & $74.35 \pm 6.68$ \\
\cline { 2 - 3 } & \multicolumn{2}{|c|}{ Good knowledge level } \\
\cline { 2 - 2 } & \multicolumn{2}{|c|}{$\mathrm{t}=8.09 \mathrm{P}=0.001$} \\
\hline
\end{tabular}

Table 3.

Distribution of the female university students regarding their level of knowledge score about Vulvovaginal Candidiasis during posttest (I) and (3) $(n=100)$

\begin{tabular}{|l|c|c|}
\hline Knowledge Regarding VVC & Post test (1) at 2 wks & post test (3) at 12 wks \\
\hline Total mean knowledge score & $81.20 \pm 5.01$ & $62.85 \pm 6.89$ \\
& Good & satisfactory \\
\cline { 2 - 3 } & $\mathrm{t}=22.58$ & $\mathrm{P}=0.001$ \\
\hline
\end{tabular}




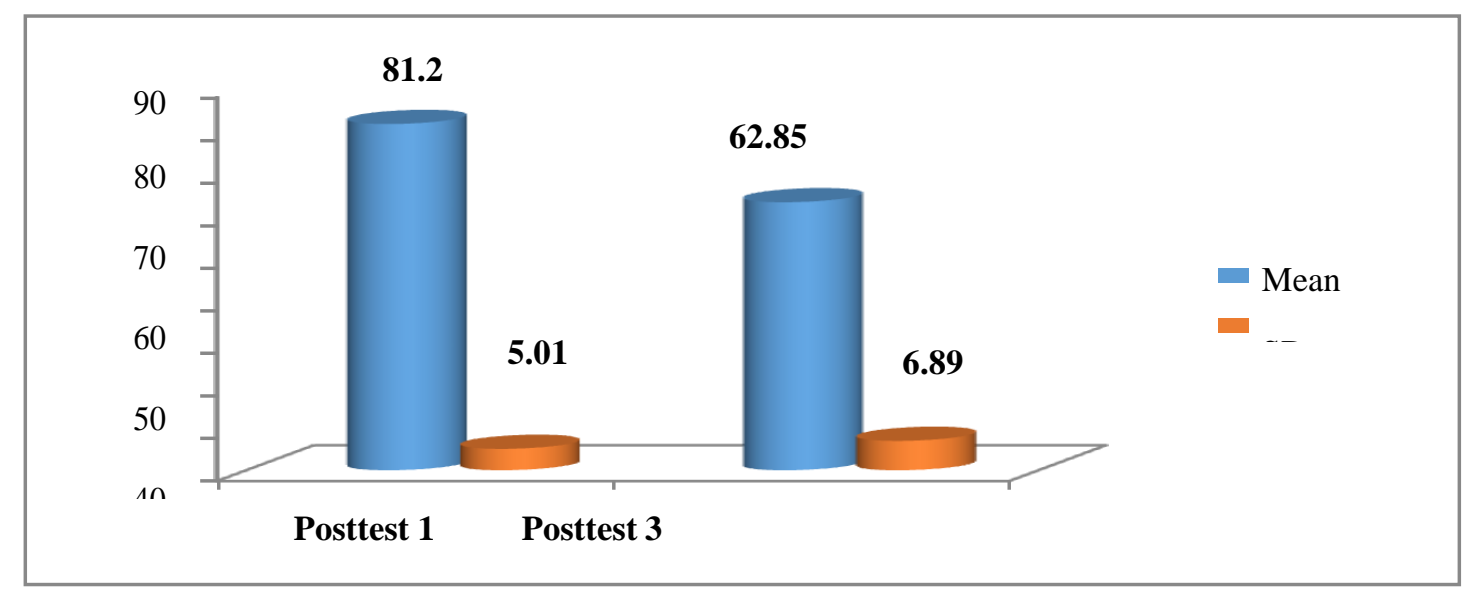

Figure 4.

Distributions of the female university students regarding their level of knowledge score about Vulvovaginal Candidiasis during posttest (I) and post test (3)

\section{DISCUSSION}

\section{Sample characteristics}

The total number of the current studied sample was 100 female university students selected from non medical faculties. The average age of the participant ranged between 18-23 years old, this result is consistent with results reported by many studies such as Chappel, 2001, \& Geiger et al., 1995; Dash, 2012, and El-Beih et al ,2014 Moreover, most of the studied sample from Faculty of Dar El-ulum and almost in second academic level (39\%). Moreover; this result is in line with Huebner (2006) who considered this age as a risk factor to VVC infection, he mentioned that younger female was vulnerable to significantly high rates of VVC infections, and infection complications.

\section{$\underline{\text { Knowledge regarding reproductive organs }}$}

Finding of the current study revealed that total mean score of pre-test knowledge regarding anatomy of reproductive organs during pre test was $5.55 \pm 4.02$ out of /14; which indicated poor knowledge, while increased to $13.69 \pm 1.46$ after two weeks from instruction program; which indicated improvement in knowledge level to became good, while after eight weeks from instruction program to $12.89 \pm 1.04$; which indicated improvement in knowledge level to became good, consequently after twelve weeks from instruction program the total mean score of knowledge was11.13 \pm 1.65 out of $/ 14$; which indicated satisfactory level, this result of the current study during pre test supported by: Haque et al, 2015 ; they reported that two group included their study had poor knowledge level regarding reproductive organs in their study of knowledge about reproductive health among urban and rural women on Bangladesh . Also supported by El-Beih et al, 2014 in their study about health practices among female university students regarding prevention of reproductive tract infections they reported that studied students had' unsatisfactory knowledge score level $(47.5 \%)$ was the pattern in relation to items related to anatomy the female reproductive system. Additionally, his could be attributed to the minor role that educational curriculum played in covering this area of knowledge. This finding is better in comparison with the results reported by Verma et al., (2011) they reported that only one quarter of the girls had good knowledge about the anatomy of the female reproductive system. This finding is in agreement with Yameen., (2005) who mentioned that half of the girls were unable to name three organs of the female reproductive system. This could be attributed to the insufficient basic information gained 
from their academic

Knowledge regarding VVC

Concerning the level of Knowledge during pre-test data showed that average of the total VVC knowledge score of participant was found to be $18.87 \pm 7.83$ out of 85 ; which indicated poor knowledge level $(22.2 \%)$ and Ninety five percent of the studied sample had good level of knowledge about VVC during the post-test (I) after two weeks from the program. With a total mean score of knowledge were (81.20 out of 85). With highly statistically significant difference in the total knowledge score level regarding VVC on the pretest and posttest $(\mathrm{P}=0.001)$ after two weeks from program. The following study finding supported the current study finding. Pratibha et al., 2014 conducted a study in Manipal, India, the result revealed that $(89.2 \%)$ had poor knowledge in pre- test; where as $95.8 \%$ had good knowledge in post-test, and Soudabeh et al ., 2002 conducted a study in Iran The findings of the current study indicated a significant increase in mean score of knowledge, and Practice of the women $(75.3 \%$ ) had poor knowledge in pre-test; where as (92.8\%) had good knowledge in post-test after one week from the program. Thankamma conducted a study in Udupi district in the Indian, the result revealed that, 13(43.33\%) participants scored good score in pre-test; this difference in results may be related to sample size, and culture. Moreover in the post test $100 \%$ of the study sample had good knowledge level

\section{CONCLUSION}

Based on the findings of the current study, it can be concluded that the female university students have poor knowledge regarding VVC and its prevention during pre test and improvement which was occurred in knowledge level to become good knowledge level (95\%) after two weeks from the instruction program. Moreover, maintain good level of knowledge during post test (2) after eight weeks and satisfactory knowledge level at post test (3) after twelve weeks from instruction program. Finally greater improvement was obvious in level of awareness regarding knowledge of VVC knowledge, as well as this results supported the research hypotheses and accepted through the findings of the previous results.

\section{ACKNOWLEDGMENT}

I would like to acknowledge the contribution of all the participants who kindly agreed to take part in the study. They generously gave their time and attention to conduct this study. This study would have been impossible without their generosity.

\section{REFERENCES}

Berek, J.S. (2007). Gynecology, (14 ${ }^{\text {th }}$ ed.). USA: Lippinocott Company, pp. 541-547.

Centers for Disease Control \& Prevention (CDC). 2014. Fungal diseases. Frequent asked question. Available:http://www.cdc.gov/fungal/diseases/candidiasis/genital/riskprevention.html

Chappel A. An exploratory study on perception and experience of females regarding vaginal candidiasis. Health Education Research Theory and Practice 2001;77:344-50. Dash B. Knowledge of adolescent girls regarding reproductive health care. The Nursing Journal of India 2012 Aug.;CIII(4):157-9. 
Ehrstorm S, Kornfed D, Rylander E. An evaluatory study to find out the relationship between chronic stress and vaginal candidiasis. Journal of Psychomatic Obstetric Gynaecology 2007;28:169-76.

El-Beih, Dawah. El Aal, A. Mohamed, Health Practices among Female University Students Regarding Preventionof Reproductive Tract Infections. Community Health Nursing, Ain Shams University, , Benha University, 2014.

Fidel PL,Jr.History and update on host defense Against vaginal candidiasis. AMJ Repro Immune (2007) 57:2-

Gilson, L., 2012. A Methodology Reader Health Policy and Systems Research. WHO Document Production Services, Geneva, Switzerland.

Gurewitsch, E.D. (2008). Guide to vaginal infections. BMJ.(333), 849-851.Available at: http://www.vaginalinfection.com/guide-to-vaginal- infection.htmpeople,

Haque, Kazi, Ahmed, Sultan, Chowdhry, and Akter. A comparative study on knowledge about reproductive health among urban and rural women on Bangladesh. Journal of Family Reprod Health. 2015 Mar; 9(1): 35-40

, available at :http://www.ncbi.nlm.nih.gov/pmc/articles/PMC4405 515/

Huebner, A. (2006): Adolescent Growth and Development. Available at: www.ext.vt.edu/pubs/family/350-850/350-850.html.

Jinping, X.U.; Schwartz, K.; Bartoces, M.; Monsur, J.; Severson, R.K. \& Sobel, J.D. (2008), Effect of Antibiotics on Valvovaginal Candidiasis Med. July- August, 21: 4 261-268.

Jose, R.b. \& Rua, C.d. (2008). Knowledge of STD/Aids among adolescent students. USP. 43: 3. Available at: ttp://dx.doi.org/10.1590/S0080- 62342009000300008.

Kamath , p. \& Pais , M\&.. Nayak ,M \& Pramila,S (2014) An awareness program on prevention of vaginalcandidiasis among pregnant women. Nitte University Journal of Health Science, NUJHS Vol. 4, No.2, June, ISSN 2249-7110

Kamath , pais , nayak , and d'souza.. 2014. an awareness program on prevention of vaginal candidiasis among pregnant women. NUJHS Vol. 4, No.2, June 2014, ISSN 2249-7110.

Kamel , A.D. (2011). Assessment of common types of vaginal infections among women attending gynecology clinics at El-Mainal University Hospital: A proposed plan of action. Published thesis at third International Arab medical conference at Libya . Available at: file:///C:/Documents and Settings/Administrator/MyDocuments/http scholar.cu.edu.eg_q=masc.

Marcia, L., Patricia, A., Ball, W.J., \& Bindeler, C.R. (2008). Maternal child nursing care, ( $2^{\text {nd }}$ ed.). USA: Pearson prentice Hall Company, pp. 104-108.

Meena, K. (2011). Study to assess the knowledge on practice regarding prevention of vaginal Candidiasis among adolescents in a selected hostel at Mangalore with a view to prepareinformation leaflet:

http://ar.scribd.com/doc/66389052/Statement- Problem-Nsg. 
Mercola, (2008). Fungus causing cancer - A novel approach to the most commonform of deathAvailableat:http://articles.mercola.com/sites/arti cles/archive/2008/08/05/fungus-causing-cancer- anovel-

Naglik, J.R.; Chauucombe, S.J.\& Hube, B. (2007) Candida albicans: secreted asparty proteinases in virulence and pathogenesis. Micro Bio Rev. 67(3), 400-428.

Rao, P.S.; Devi, S. \& Shriyan. (2005). Knowledge and practice about genital infection. Indian Journal of Medical Microbiology. Apr; 72 (4), 287-91.

Ricci, S.S., \& Kyle, T. (2011). Maternity and pediatric nursing. $2^{\text {nd }}$ Ed; USA: Lippinocott Williams, Wilkins Company, pp. 145-153.

Rylander, E.; Berglund, A.L.; Krassny, C. \& Petrini, B. (2004). Valvovaginal Candida in a young sexually active population: prevalence and association with oro-genital sex and frequent pain at intercourse. Sex Transm Infect. 80: 54-57. Available at: www.stijournal.com

Verma, P., Bhalanik, K., and Pandya, C. (2011): Reproductive Health Awareness \& Behavior of Adolescents Girls of Bhavnagar (Gujarat), Indian J. Prev. Soc. Med; 42(1).

Yameen, K. (2005): The Effect of Health Promotion Education Program on Reproductive Health Knowledge, Attitudes\& Practices (KAP) among Reproductive Age Women in Rural Palestinian Community, Master Thesis, An-Najah National University, Nablus, Palestine. P40. 
Indonesian Journal of Global Health Research, Vol 1 No 1, November 2019, pp. 47 - 58 Global Health Science Group 